\title{
Management of severe chest pain caused by a Bravo pH monitoring capsule
}

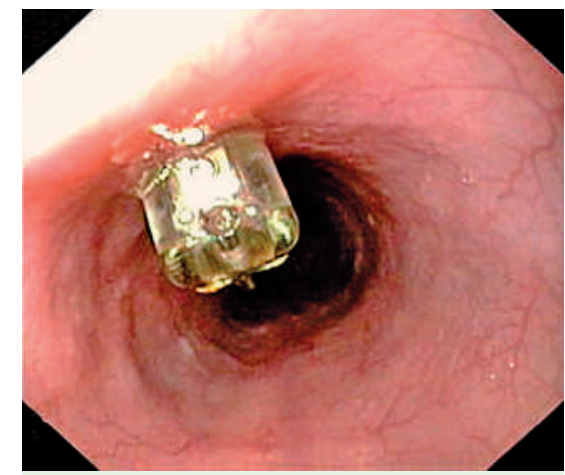

Fig. 1 Endoscopic view of a correctly attached Bravo capsule.

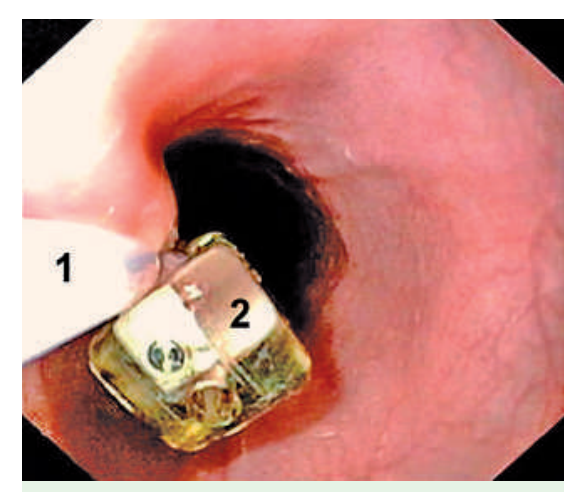

Fig. 2 A polypectomy snare (1) positioned around the site of fixation of the Bravo capsule to the esophageal wall (2).

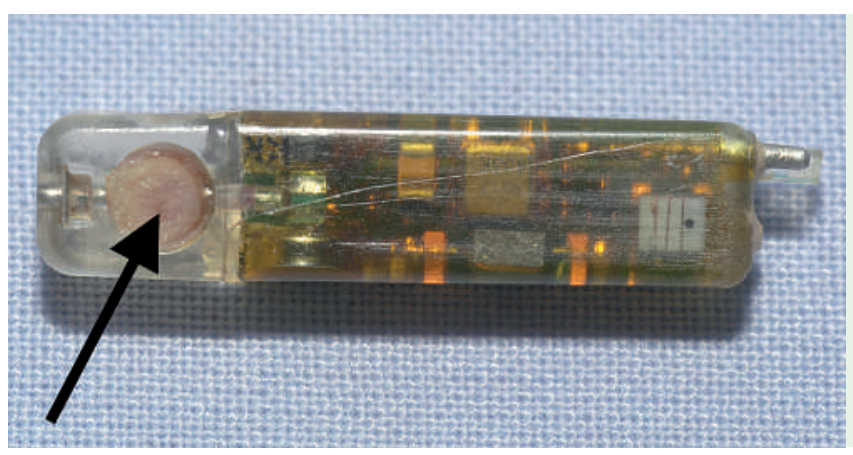

Continuous ambulatory pH-metry with the Bravo "catheter-free" monitoring system (Medtronic, Minneapolis, Minnesota, USA) is becoming more and more popular $[1-3]$. As experience with this technique has grown, it has become evident that up to $50 \%$ of patients report mild chest pain [2-4] or even severe chest pain requiring endoscopic removal of the capsule $[3,5]$. We have also had three patients with insupportably severe chest pain that occurred 2-3 hours after placement of a Bravo capsule. Because treatment with analgesics was ineffective we decided to remove the first capsule after 2 days. The pain ceased promptly. On the basis of our experience with this patient, we removed the capsules immediately after completion of 24 hours of recording in the other two patients.

We tried to remove the first capsule ( $\bullet$ Fig. 1) by exerting gentle pressure with the tip of the endoscope [5], grasping it with a biopsy forceps in an attempt to push it off the mucosa [3]. However, the capsule was attached too firmly and could not be dislodged. We eventually placed a polypectomy snare around the capsule ( Fig. 2 ) and were able to detach it easily from the esophageal wall with electrocautery. The capsule was recovered using the same snare ( $\bullet$ Fig. 3 ), leaving only a small mucosal defect similar to that left after a small mucosectomy ( $\mathbf{F i g . 4}$ ). This procedure appears to be fairly safe because only mucosa and not the whole esophageal wall can be aspirated due to the small size of the vacuum well in the capsule ( $\bullet$ Fig. 5). Detaching the capsule with a polypectomy snare would therefore be very unlikely to cause an iatrogenic esophageal perforation. Furthermore, no bleeding will occur due to the electrocautery.

Endoscopic removal of the capsule with a polypectomy snare is a reasonable treatment strategy in the event of capsule-induced severe chest pain. This method seems safe and prevents bleeding from the mucosa.

Endoscopy_UCTN_Code_CPL_1AH_2AJ 
A. Fischer, P. K. Baier, S. Utzolino, U. T. Hopt, H. J. Schrag

Department of General and Visceral Surgery, Albert-Ludwigs-University, Freiburg, Germany

\section{References}

1 Gillies RS, Stratford JM, Booth MI, Dehn TC. Oesophageal $\mathrm{pH}$ monitoring using the Bravo catheter-free radio capsule. Eur J Gastroenterol Hepatol 2007; 1: 57-63

2 Wong WM, Bautista J, Dekel R et al. Feasibility and tolerability of transnasal/per-oral placement of the wireless $\mathrm{pH}$ capsule vs. traditional 24-h oesophageal $\mathrm{pH}$ monitoring: a randomized trial. Aliment Pharmacol Ther 2005; 2: 155- 163

3 Pandolfino JE, Richter JE, Ours Tet al. Ambulatory esophageal $\mathrm{pH}$ monitoring using a wireless system. Am J Gastroenterol 2003; 4: $740-749$

4 Lee YC, Wang HP, Chiu HM et al. Patients with functional heartburn are more likely to report retrosternal discomfort during wireless $\mathrm{pH}$ monitoring. Gastrointest Endosc 2005; 6: 834-841

5 Triester SL, Leighton JA, Budavari AI et al. Severe chest pain from an indwelling Bravo pH probe. Gastrointest Endosc 2005; 2: 317-319
Bibliography

DOI $10.1055 / \mathrm{s}-2007-967058$

Endoscopy 2008; 40: E55-E56

(c) Georg Thieme Verlag KG Stuttgart · New York . ISSN 0013-726X

\section{Corresponding author}

\section{A.Fischer, MD}

Surgical Endoscopy

Department of General and Visceral Surgery Albert-Ludwigs-University

Hugstetterstr. 55

79106 Freiburg

Germany

Fax: +49-7612702570

andreas.fischer@uniklinik-freiburg.de 